\title{
Transport of U(VI) through sediments amended with phosphate to induce in situ uranium immobilization
}

Vrajesh S. Mehta ${ }^{\mathrm{a}}$, Fabien Maillot ${ }^{\mathrm{b}}$, Zheming Wang $^{\mathrm{c}}$, Jeffrey G. Catalano ${ }^{\mathrm{b}}$ and Daniel E. $\operatorname{Giammar}^{\mathrm{a}, *}$

${ }^{a}$ Department of Energy, Environmental and Chemical Engineering, Washington University in St. Louis, St. Louis, Missouri, 63130, United States of America

${ }^{\mathrm{b}}$ Department of Earth and Planetary Sciences, Washington University in St. Louis, St. Louis, Missouri, 63130, United States of America

${ }^{c}$ Department of Fundamental and Computational Sciences Directorate, Pacific Northwest National Laboratory, Richland, Washington, 99352, United States of America

* Corresponding author. Tel.: 314-935-6849. Fax.: 314-935-7211.

E-mail address: giammar@wustl.edu (Daniel E. Giammar, 1 Brookings Drive, Campus Box 1180, St. Louis, Missouri, 63130, United States of America)

Revised manuscript submitted to Water Research

October 2014 


\section{Abstract}

Phosphate amendments can be added to U(VI)-contaminated subsurface environments to

3 promote in situ remediation. The primary objective of this study was to evaluate the impacts of

4 phosphate addition on the transport of U(VI) through contaminated sediments. In batch

5 experiments using sediments ( $<2 \mathrm{~mm}$ size fraction) from a site in Rifle, Colorado, U(VI) only

6 weakly adsorbed due to the dominance of the aqueous speciation by $\mathrm{Ca}-\mathrm{U}(\mathrm{VI})$-carbonate

7 complexes. Column experiments with these sediments were performed with flow rates that

8 correspond to a groundwater velocity of $1.1 \mathrm{~m} /$ day. In the absence of phosphate, the sediments

9 took up $1.68-1.98 \mu \mathrm{g} \mathrm{U} / \mathrm{g}$ of sediments when the synthetic groundwater influent contained 4

$10 \mu \mathrm{M} U(\mathrm{VI})$. When U(VI)-free influents were then introduced with and without phosphate,

11 substantially more uranium was retained within the column when phosphate was present in the

12 influent. Sequential extractions of sediments from the columns revealed that uranium was

13 uniformly distributed along the length of the columns and was primarily in forms that could be

14 extracted by ion exchange and contact with a weak acid. Laser induced fluorescence

15 spectroscopy (LIFS) analysis along with sequential extraction results suggest adsorption as the

16 dominant uranium uptake mechanism. The response of dissolved uranium concentrations to

17 stopped-flow events and the comparison of experimental data with simulations from a simple

18 reactive transport model indicated that uranium adsorption to and desorption from the sediments

19 was not always at local equilibrium.

20 Keywords: Uranium, Phosphate, In Situ Immobilization, Reactive transport, Sequential

21 extractions, CXTFIT 


\section{Introduction}

Uranium contamination of soil and groundwater at more than 120 sites across 36 states in the United States has occurred as a result of activities associated with production of nuclear materials (Palmisano and Hazen 2003). The widespread contamination at many sites makes it economically challenging to use pump-and-treat or excavation methods for remediation. An alternative approach is to manipulate the chemical or physical conditions of the subsurface environment to promote in situ immobilization of uranium via formation of stable solid forms of uranium (Ahmed et al. 2012, Crane et al. 2011, Sharp et al. 2011a). Two widely studied classes of solids are $\mathrm{U}(\mathrm{IV})$ oxides $\left(\mathrm{UO}_{2+\mathrm{x}}\right)$ with uraninite $\left(\mathrm{UO}_{2}\right)$ as the pure oxide form and autunitegroup $\mathrm{U}(\mathrm{VI})$ phosphate solids that include autunite $\left(\mathrm{Ca}\left(\mathrm{UO}_{2}\right)_{2}\left(\mathrm{PO}_{4}\right)_{2}\right)$, sodium autunite $\left(\mathrm{Na}_{2}\left(\mathrm{UO}_{2}\right)_{2}\left(\mathrm{PO}_{4}\right)_{2}\right)$, and chernikovite $\left(\mathrm{H}_{3} \mathrm{O}\left(\mathrm{UO}_{2}\right)\left(\mathrm{PO}_{4}\right) \cdot 3 \mathrm{H}_{2} \mathrm{O}\right)$. Addition of phosphate amendments to $\mathrm{U}(\mathrm{VI})$-contaminated subsurface environments has been evaluated in laboratory and field studies as a potential in situ remediation method (Arey et al. 1999, Beazley et al. 2011, Fuller et al. 2002, Mehta et al. 2014, Wellman et al. 2008). Phosphate addition can immobilize uranium by inducing the precipitation of low solubility $\mathrm{U}(\mathrm{VI})$ phosphate solids (Jensen et al. 1996, Singh et al. 2010). Various U(VI) phosphates have been observed at uraniumcontaminated field sites (Arai et al. 2007, Buck et al. 1996, Catalano et al. 2006, Jones et al. 2001, Singer et al. 2009) and are also found in some ore settings without external addition of phosphate (Jerden et al. 2003).

In addition to helping to precipitate $\mathrm{U}(\mathrm{VI})$ solids, phosphate can influence $\mathrm{U}(\mathrm{VI})$ adsorption to mineral surfaces. Uranium sorption by ferrihydrite and goethite was enhanced in the presence of phosphate at weakly acidic $\mathrm{pH}$ because of the strong surface binding of phosphate and subsequent formation of ternary surface complexes (Cheng et al. 2004, Payne et 
al. 1996, Singh et al. 2012). The presence of reactive mineral surfaces, like those of iron oxides

51 and clays, can potentially limit the precipitation of U(VI) phosphate solids by adsorbing

52 dissolved U(VI) and phosphate to make the solution less saturated with respect to potential

53 precipitates or may facilitate heterogeneous nucleation of precipitates (Singh et al. 2010). Even

$54 \mathrm{U}(\mathrm{VI})$ adsorption to calcium phosphate mineral surfaces can decrease the dissolved

55 concentration of U(VI) to prevent U(V) phosphate precipitation (Fuller et al. 2002).

The primary objective of this study was to determine the impacts of phosphate addition

57 on the transport of U(VI) through columns loaded with sediments from an environmentally

58 relevant field site in Rifle, Colorado. Batch and column experiments were performed using these

59 sediments with solutions that simulated the groundwater composition at the field site. Batch

60 experiments were used to calculate the equilibrium uranium sorption capacity of Rifle sediments

61 with synthetic groundwater in the absence and presence of added phosphate. Column

62 experiments involved analysis of the influent and effluent solutions, reactive transport modeling,

63 and characterization of the reacted sediments by sequential extractions and fluorescence

64 spectroscopy. Insight into the processes controlling the impact of phosphate on U(VI) transport

65 can help identify conditions that lead to the greatest reductions in U(VI) mobility.

66

67

\section{Materials and Methods}

\subsection{Materials}

All chemicals used in this study were ACS grade or better. Stock solutions were prepared in ultrapure water (>18.2 M $\Omega$-cm resistivity). Background sediments ( $<2 \mathrm{~mm}$ size fraction) from a uranium-contaminated site in Rifle, Colorado were used as the porous medium. Detailed characterization of these sediments has been reported previously (Campbell et al. 2012, Komlos et al. 2008). Campbell and co-workers reported that the background sediment samples have up 
73 to $1.7 \mu \mathrm{g} \mathrm{U} / \mathrm{g}$ of sediments as determined from nitric acid extraction. XRD analysis of the

74 sediments revealed the presence of quartz and plagioclase and potassium feldspars, with lesser

75 amounts of amphibole, calcite, and clays. The clay size fraction is dominated by illite and

76 smectite with minor amounts of chlorite and kaolinite. Mössbauer spectroscopy performed by

77 Komlos et al. (2008) showed that iron is predominantly hosted in silicates and Al-rich goethite;

78 the iron oxides hematite, magnetite, and ferrihydrite are also present but at lesser abundance.

\section{$79 \quad 2.2$ Methods}

$80 \quad 2.2 .1 \quad$ Batch sorption experiments

81 The sediments were pre-equilibrated with synthetic Rifle groundwater (SRGW) (Table 1) under

82 a $2.7 \% \mathrm{CO}_{2}$ environment for 2 days under well-mixed conditions at a solids loading of $250 \mathrm{~g} / \mathrm{L}$.

83 SRGW was prepared to simulate the conditions at the field site (Campbell et al. 2011, DOE

84 1999). This step was included to remove any labile background uranium. After pre-equilibration

85 the sediments were separated from the solution and contacted with freshly prepared SRGW,

86 spiked with varying concentrations of uranium $(0.1-100 \mu \mathrm{M})$ and phosphate $(0-1000 \mu \mathrm{M})$,

87 and equilibrated for 2 days. Samples were then collected, filtered using $0.22 \mu \mathrm{m}$ filters, and

88 acidified to $1 \% \mathrm{HNO}_{3}$ for elemental analysis. For the phosphate-free experiments and the lowest

89 concentrations of $\mathrm{U}(\mathrm{VI})$, even after pre-equilibration some of the adsorption experiments resulted

90 in final dissolved $\mathrm{U}$ concentrations greater than the initial concentrations. These samples were

91 not included in the linear adsorption isotherm determination.

$92 \quad$ 2.2.2 Column experiments

93 Column experiments were conducted at room temperature $\left(22 \pm 0.5{ }^{\circ} \mathrm{C}\right)$. Sediments were wet-

94 loaded into glass columns ( $2.5 \mathrm{~cm}$ diameter $\mathrm{x} 15 \mathrm{~cm}$ length) and retained using porous plates (20 
$95 \mu \mathrm{m}$ pore size) that also helped to distribute flow evenly to the column cross-section. This method 96 resulted in porosity $(\theta)$ of $0.32-0.38$ as determined from measurements of the sediment mass,

97 total column volume, and volume of water needed to saturate the pore space. Plastic bags that

98 were impermeable to gases (e.g., $\mathrm{O}_{2}$ and $\mathrm{CO}_{2}$ ) were used to store the SRGW, which allowed 99 introduction of solutions with dissolved inorganic carbon concentration and solution $\mathrm{pH}$ that 100 mimicked those at the actual site but that would have resulted in $\mathrm{CO}_{2}$ exsolution to the ambient 101 laboratory atmosphere. The SRGW was introduced into the columns in an upflow mode using a 102 peristaltic pump at a rate $(8 \mathrm{~mL} / \mathrm{h})$ that corresponded to a linear velocity of $\sim 1.1 \mathrm{~m} / \mathrm{d}$, which was 103 in the range observed at the site (Fang et al. 2009, Moon et al. 2010, Yabusaki et al. 2007). to the columns with or without uranium and phosphate. A conditioning mode during which SRGW that did not contain uranium and phosphate was included to remove the background 107 labile fraction of uranium from the sediments. Columns were then operated in an uptake mode 108 until with $4 \mu \mathrm{M} \mathrm{U}(\mathrm{VI})$ in the influent until uranium breakthrough occurred. Finally a release mode was performed with uranium-free influents both with and without added phosphate. 110 Bromide was included as a conservative tracer for calculating hydrodynamic transport 111 parameters. A stopped flow technique described by (Brusseau et al. 1997) was used to observe 112 the effects of non-equilibrium processes on uranium uptake and release. In this method, the flow 113 was stopped to the columns for 12-hour periods and then restarted. Examination of the extent of 114 uranium uptake by or release from the sediments during this stagnant period provides 115 information regarding the mass transfer of chemical kinetic limitations to solid-water exchange 116 of uranium. Column experiments were terminated at different times, and sediment samples were 117 collected in increments from various depths (roughly $5 \mathrm{~cm}$ each) to study the speciation and 
118 spatial distribution of uranium along the length of the column. The current study represents a 119 scenario of a site with a relatively stable plume of uranium-contaminated groundwater into 120 which phosphate solution is introduced.

121 Thermodynamic calculations using the latest critically reviewed database for uranium and 122 relevant reactions (Mehta et al. 2014) determined that the SRGW solution was undersaturated 123 with respect to any uranium solid phase. In the absence of phosphate, the solution was slightly 124 supersaturated $(\mathrm{SI}=0.33)$ with respect to calcite. In the presence of phosphate, the solution was 125 supersaturated with calcium phosphates that included hydroxylapatite and octacalcium 126 phosphate; however, no precipitates were visibly present in the influent reservoirs and influent 127 samples indicated no loss of calcium or phosphate from the influent solution.

128 2.2.3 Chemical analysis of influent and effluent

129 Samples (influent and effluent) were regularly collected, analyzed for $\mathrm{pH}$ and bromide 130 concentration, saved for dissolved inorganic carbon (DIC) analysis, and preserved for elemental 131 analysis by acidifying to $1 \% \mathrm{HNO}_{3}$. Dissolved concentrations of $\mathrm{U}, \mathrm{P}, \mathrm{Ca}, \mathrm{Na}, \mathrm{Mg}, \mathrm{K}$ and $\mathrm{Si}$ 132 were measured using inductively coupled plasma-mass spectrometry (ICP-MS, Perkin Elmer 133 Elan DRC II). The ICP-MS detection limit was $0.1 \mu \mathrm{g} / \mathrm{L}$ for uranium, $10 \mu \mathrm{g} / \mathrm{L}$ for phosphorus, 134 and $50 \mu \mathrm{g} / \mathrm{L}$ for other measured elements. DIC was measured using a TOC analyzer (Shimadzu, 135 TOC-L $\mathrm{CPH}_{\mathrm{CPN}}$ PC-controlled model). Bromide was measured with an ion selective electrode 136 (Cole-Parmer).

\subsubsection{Calculation of transport parameters}

138 Bromide and uranium breakthrough and washout curves were used to calculate various transport 139 parameters using the CXTFIT-Excel tool (Tang et al. 2009) originally based on the FORTRAN 
140 version (Parker and Van Genuchten 1984) and modified by (Toride et al. 1995) to include the

141 convection dispersion equation (CDE) solving capabilities. Equation 1 represents the generic

142 form of the CDE assuming one-dimensional steady flow in a homogenous, isotropic porous

143 medium.

$R \frac{\partial C}{\partial t}=D_{L} \frac{\partial^{2} C}{\partial x^{2}}-v \frac{\partial C}{\partial x}+r$

144 where $\mathrm{C}=$ concentration in liquid phase $\left[\mathrm{mol} / \mathrm{m}^{3}\right], \mathrm{t}=$ time $[\mathrm{s}], \mathrm{D}_{\mathrm{L}}=$ longitudinal hydrodynamic

145 dispersion coefficient $\left[\mathrm{m}^{2} / \mathrm{s}\right], x=$ distance $[\mathrm{m}], v=$ average linear velocity $[\mathrm{m} / \mathrm{s}]$, and $\mathrm{r}$ indicates

146 the rate of a biological or chemical reaction (production/sink) $\left[\mathrm{mol} / \mathrm{m}^{3}-\mathrm{s}\right]$ of the solute other than

147 sorption. $\mathrm{R}$ is the retardation factor, which is related to the partition coefficient $\left(\mathrm{K}_{\mathrm{d}}\right)\left[\mathrm{m}^{3} / \mathrm{kg}\right]$ as

148 shown in equation 2.

$149 \quad R=1+\frac{\rho_{\mathrm{b}} \mathrm{K}_{d}}{\theta}$

150 where, $\rho_{\mathrm{b}}$ is the bulk density $\left(\mathrm{kg} / \mathrm{m}^{3}\right)$ and $\theta$ is the porosity. As determined from the known

151 column volume and the measured masses of the sediments and the water-saturated column,

152 values of $\rho_{\mathrm{b}}$ ranged from 1740 to $1810 \mathrm{~kg} / \mathrm{m}^{3}$ and values of $\theta$ varied from $0.32-0.38$ for

153 different columns.

154 Equations 3 and 4 represent the dimensionless non-equilibrium CDE. The model is based on the

155 assumption that the aqueous phase can be partitioned into mobile and immobile regions.

$$
\begin{aligned}
& \beta R \frac{\partial C_{m}}{\partial T}=\frac{1}{P e} \frac{\partial^{2} C_{m}}{\partial X^{2}}-\frac{\partial C_{m}}{\partial X}-\omega\left(C_{m}-C_{i m}\right) \\
& (1-\beta) R \frac{\partial C_{i m}}{\partial T}=\omega\left(C_{m}-C_{i m}\right)
\end{aligned}
$$


156 where $\mathrm{T}=v \mathrm{t} / \mathrm{L}$ and $\mathrm{X}=x / \mathrm{L}$ are dimensionless representations of time and distance along

157 the column, and subscripts $m$ and im indicate the mobile and immobilize zones respectively.

158 Fitting of the model to experimental data was used to calculate the dimensionless parameters $\omega$

159 and $\beta$ in equations 3 and 4 . These parameters from the non-equilibrium CDE are then further

160 based on properties of the columns and the processes indicated in equations 5 and 6.

$$
\omega=\frac{\alpha L}{\theta v}
$$

$161 \beta=\frac{\theta_{m}+f \rho_{b} K_{d}}{\theta+\rho_{b} K_{d}}$

162 where $\alpha$ is the first-order mass transfer coefficient $\left(\mathrm{s}^{-1}\right)$ governing the rate of solute exchange 163 between the mobile and immobile liquid regions and $\mathrm{f}$ is the fraction of adsorption sites that 164 equilibrates with the mobile liquid phase.

165 As would be expected for a non-reactive solute, bromide transport was not retarded through the 166 column and its $\mathrm{R}$ value was set to 1 . Effluent bromide and uranium data were simultaneously fit 167 to determine the Peclet number $(\mathrm{Pe})$, mobile water fraction $(\beta)$, mass transfer coefficient $(\omega)$ and 168 uranium retardation factor $(\mathrm{R})$. The dispersivity $(\lambda$ in $\mathrm{cm})$ was determined using the Peclet 169 number and length (L) of the column (Equation 7).

$170 \quad P_{e}=\frac{L}{\lambda}=\frac{L v}{D_{L}}$

171 The retardation coefficient obtained through fitting was used to calculate the value of the 172 partition coefficient $\mathrm{K}_{\mathrm{d}}$.

$173 \quad 2.2 .5 \quad$ Sequential extractions 
174 Sediments were collected in roughly three equal sections along the length of the column at the 175 end of each experiment and classified as those from the inlet, midsection, and outlet. Extractions 176 were performed in duplicate for all the column samples. A four step sequential extraction method 177 (Table 2) modified from (Tessier et al. 1979) with a solid to solution ratio of $40 \mathrm{~g} / \mathrm{L}$ (34 g dry 178 weight/L based on moisture content measurements) in 50-mL reactors was used to evaluate the 179 solid phase speciation and spatial distribution of uranium. A single step total digestion using a 180 mixture of nitric acid and hydrochloric acid at $100^{\circ} \mathrm{C}$ for $4 \mathrm{~h}$ was also performed to more 181 directly measure the total uranium content for comparison with the total content determined from 182 the sum of the uranium amounts from the four steps of the sequential extraction. This hot acid 183 extraction was determined to fully extract the uranium in the sediments based on comparisons 184 with published total uranium contents for the site (Campbell et al., 2012) and in quality control 185 tests using standard reference materials that indicated complete uranium recovery.

\subsubsection{Laser induced fluorescence spectroscopy (LIFS) analysis}

187 Sediment samples from different depths within a column were loaded into $2 \mathrm{~mm} \times 4 \mathrm{~mm} \times 25$ mm quartz cuvettes for analysis. Instrumentation and experimental procedures for LIFS analysis

189 have been described previously (Wang et al. 2004, Wang et al. 2005). The quartz cuvettes were 190 attached to the cold finger of a CRYO Industries RC152 cryostat with liquid helium vaporizing 191 beneath the sample to reach a sample temperature of $8 \pm 2 \mathrm{~K}$. The samples were excited with a 192 Spectra-Physics Nd:YAG laser-pumped Lasertechnik-GWU MOPO laser at $415 \mathrm{~nm}$, and the 193 emitted light was collected at $85^{\circ}$ to the excitation beam and detected with a thermoelectrically 194 cooled Princeton Instruments PIMAX intensified CCD camera after spectral dispersion through an Acton SpectroPro 300i double monochromator spectrograph. The spectra were analyzed using

196 the commercial software IGOR (Wavematrix, Inc). 


\section{Results and discussion}

\subsection{Batch sorption experiments}

Increasing phosphate concentrations $(0-1000 \mu \mathrm{M})$ resulted in increased uranium uptake for starting uranium concentrations of $0.1-100 \mu \mathrm{M}$ (Figure 2). For a linear adsorption isotherm, $\mathrm{K}_{\mathrm{d}}$ values of $0.4,0.6$ and $2.2 \mathrm{~mL} / \mathrm{g}$ are calculated for 0,100 and $1000 \mu \mathrm{M}$ phosphate concentrations, respectively. Increased uranium uptake caused by phosphate could be due to the formation of inner-sphere U(VI)-phosphate ternary surface complexes that have previously been observed in the presence of phosphate and various iron-oxides (Bostick et al. 2002, Cheng et al. 2004, Payne et al. 1996, Singh et al. 2010). Uranium adsorption onto Rifle sediments could occur through cation exchange to interlayer sites in clays and inner-sphere binding to iron oxide surfaces or to edge sites on clays like montmorillonite. Surface complexes could include binary surface complexes as well as ternary surface complexes with phosphate as noted above as well as ternary surface complexes with carbonate (Bargar et al. 1999, Bernhard et al. 2001, Sherman et al. 2008). Both iron oxides and clays are present in this sediment (Campbell et al. 2012, Komlos et
al. 2008).

Previous batch studies on uranium sorption in the absence of phosphate using background sediments from the Rifle site have measured $\mathrm{K}_{\mathrm{d}}$ values up to $1.25 \mathrm{~mL} / \mathrm{g}$ at $\mathrm{pH} 7.2$ and $2.6 \%$ $\mathrm{CO}_{2}$ conditions (Hyun et al. 2009); the present study had $\mathrm{pH} 7.1$ and $\sim 2.7 \% \mathrm{CO}_{2}$. Adsorption of U(VI) by the Naturita aquifer sediments (another former uranium milling site in Colorado) had $\mathrm{K}_{\mathrm{d}}$ values of $\sim 3 \mathrm{~mL} / \mathrm{g}$ at $1.6 \% \mathrm{CO}_{2}$ (Davis et al. 2004). The lower $\mathrm{K}_{\mathrm{d}}$ values under phosphate-free conditions observed in the present study may be due to slight differences in the chemical compositions of the solutions and to differences in the properties of the sediments collected at different sites or from different locations of the Rifle site. Several studies have found 
$220 \mathrm{~K}_{\mathrm{d}}$ values to be very sensitive to $\mathrm{CO}_{2}$ conditions (Hyun et al. 2009, Kohler et al. 1996, Reardon

221 1981). The higher calcium concentration (5 mM) in this study as compared to the $3 \mathrm{mM}$ in Hyun

222 et al. (2009) could also have inhibited sorption. For SRGW, in the presence or absence of

223 phosphate, the $\mathrm{U}(\mathrm{VI})$ predominantly exist as $\mathrm{Ca}_{2} \mathrm{UO}_{2}\left(\mathrm{CO}_{3}\right)_{3}(\sim 87 \%)$ followed by

$224 \mathrm{CaUO}_{2}\left(\mathrm{CO}_{3}\right)_{3}{ }^{2-}(\sim 13 \%)$. Higher calcium concentrations decrease U(VI) adsorption due to

225 formation of stable aqueous $\mathrm{Ca}-\mathrm{UO}_{2}-\mathrm{CO}_{3}$ ternary complexes (Bernhard et al. 1998, Bernhard et 226 al. 2001, Dong and Brooks 2006, Stewart et al. 2010). Overall, the extent of adsorption to 227 sediments with appreciable carbonate concentrations is lower than to other materials; batch 228 adsorption experiments with sediments from the Oak Ridge, Savannah River, and Hanford Sites 229 all had greater adsorption affinities for uranium than did the Rifle sediments. For these 230 sediments, uranium desorption consistently decreased when the carbonate concentration was 231 increased (Barnett et al. 2000). Hence, the extent of immobilization at the Rifle site is likely 232 limited due to the high carbonate concentration.

The $\mathrm{K}_{\mathrm{d}}$ values determined in the present study and previous work for the Rifle site are 234 overall much lower than those determined for sediments from other sites. $\mathrm{K}_{\mathrm{d}}$ values of $14-22$ $235 \mathrm{~mL} / \mathrm{g}, 51-95 \mathrm{~mL} / \mathrm{g}$ and $40-30000 \mathrm{~mL} / \mathrm{g}$ have been determined for sediments from the Hanford 236 site in Washington (Qafoku et al. 2005), Oak Ridge site in Tennessee (Stewart et al. 2010) and F237 area Savannah River site in South Carolina (Dong et al. 2011), respectively. Differences in 238 sediment mineralogy and groundwater composition may explain the different adsorption 239 affinities found at various sites.

\section{$240 \quad 3.2$ Uranium uptake and release in the absence of phosphate}

$241 \quad 3.2 .1 \quad$ Aqueous phase analysis 
242 The conditioning mode flushed an appreciable amount $(0.2 \mu \mathrm{g} / \mathrm{g})$ of labile uranium from the

243 initial sediments (Figure 3). During the uptake mode similar bromide breakthrough profiles were

244 observed for all columns. As a conservative tracer, bromide concentrations increased rapidly to

245 reach the influent level within 4 pore volumes (PV) as compared to $\sim 35 \mathrm{PV}$ required for

246 uranium to achieve complete breakthrough (Figure 3). The greater pore volumes for U(VI)

247 breakthrough directly indicate that its transport was retarded by adsorption to the sediments.

248 Calculations based on a simple mass balance approach (equation 8) that accounts for the

249 difference in influent and effluent concentrations determined uranium uptake of up to $1.98 \pm 0.14$

$250 \mu \mathrm{g} / \mathrm{g}$ of sediments (Table 3 ).

$U_{\text {mass }}$ uptaken $\left(\frac{\mu g}{g}\right)=\frac{\sum\left[\left(C_{\text {in }}-C_{\text {out }}\right) * Q * t\right]}{m_{\text {sed }}}$

251 where $C_{\text {in }}$ and $C_{\text {out }}$ are the measured uranium concentrations $(\mu \mathrm{g} / \mathrm{L}), \mathrm{Q}$ is the flow rate $(\mathrm{L} / \mathrm{h}), \mathrm{t}$ is

252 the total time of flow at a given concentration $(\mathrm{h})$, and $\mathrm{m}_{\text {sed }}$ is the mass of sediments in the

253 column $(\mathrm{g})$. The uncertainty estimates reported in Table 3 come from the propagation of

254 uncertainty across the 10 or more effluent samples used in the summation in equation 8.

255 Uranium release was initiated following the uptake mode by introducing uranium-free

256 SRGW both without (Column B) and with(Columns C and D) phosphate. In the absence of

257 phosphate, all of the uranium that had been taken up during loading was desorbed from the

258 sediments within $100 \mathrm{PV}$.

The stopped flow events revealed noticeable non-equilibrium sorption behavior for all

260 columns. For these events during the uptake mode, the uranium concentrations were lower when

261 flow was resumed than immediately before it was stopped, which indicates that during stopped

262 flow the uranium was taken up by processes that could not reach local equilibrium with flowing 
263 water. Uranium release was also influenced by the stopped flow event wherein the uranium

264 concentrations increased when there was no flow. A similar phenomenon was observed for

265 Hanford sediments in column experiments (Qafoku et al. 2005) in which the magnitude of

266 change in concentrations was proportional to the duration of stopped flow. For 24-h stopped flow

267 events with Hanford sediments, the U(VI) concentrations decreased by $<10 \%$ during the

268 adsorption phase. In the current study with only $12 \mathrm{~h}$ stopped flow events, the U(VI)

269 concentrations decreased by $\sim 10 \%$ during the adsorption phase.

Non-equilibrium uranium adsorption could occur due to chemical (different adsorption

271 kinetics) and/or physical (intraparticle diffusion) processes. Since the adsorption of U(VI) to

272 mineral surfaces is generally fast, typically attaining equilibrium within few minutes (Giammar

273 and Hering 2001, Hsi and Langmuir 1985), the non-equilibrium U(VI) adsorption behavior is

274 believed to result from physical mass transfer processes. For example physical non-equilibrium

275 models have been used previously to successfully simulate uranium transport in column and

276 field-scale studies (Fox et al. 2012, Greskowiak et al. 2011, Qafoku et al. 2009). The non-

277 equilibrium behavior of uranium in this study has thus been attributed to the intragrain

278 diffusional mass transfer limitations existing within local micro-environments.

$279 \quad 3.2 .2$ Simulating the reactive transport of uranium

280 Adsorption and release profiles for both uranium and bromide were fitted simultaneously for 281 column B (Figure 4a), and only the adsorption profiles for uranium were fitted for columns A, C 282 and D (Figure 4b). The desorption profiles for column C and D were not fitted because CXTFIT 283 can only be used to fit adsorption-desorption modes with the same composition. It was likely that 284 in the presence of phosphate, reactions other than adsorption-desorption of uranium were also 285 occuring, and CXTFIT can only account for processes like adsorption that can be interpreted 
using a simple partition constant. To be consistent with the stopped flow event observations, which indicated that local equilibrium was not achieved for the mobile fluid residence times of the experiments, a non-equilibrium CDE model using a single set of parameters was used to simulate uranium transport. Values of 4.62 for Pe, 0.55 for $\beta$, and 0.98 for $\omega$ provided the optimal fits to the data (Figure 4). These values yielded an $\mathrm{f}$ value of $0.50, \lambda$ of $3.25 \mathrm{~cm}$ and $\alpha$ ranging from $2.6 \times 10^{-5}$ to $3.1 \times 10^{-5} \mathrm{~s}^{-1}$. The Peclet number is consistent with longitudinal transport being primarily controlled by advection. The value of $\mathrm{f}$ indicates that the pore water is evenly distributed (i.e. 50\% / 50\%) between mobile and immobile phases. The $\alpha$ values are sufficiently large that even with $50 \%$ of the surface sites contained in immobile water the transfer of solutes from the mobile to immobile regions still allows considerable adsorption to intragranular sites to occur during flow. Values ranging from $0.19-2.99$ and $0.37-0.60$ have been reported for $\omega$ and $\beta$, respectively, from similar fitting of column experiments with clayey soils and investigation of tritiated water $\left({ }^{3} \mathrm{H}_{2} \mathrm{O}\right)$ and boron (B) transport (Tang et al. 2009). The fitting exercise involved estimation of multiple parameters $(\mathrm{Pe}, \beta, \mathrm{R}$ and $\omega)$ simultaneously to yield the optimal fit of the model to the data; however, other combinations of parameters may also be able to provide reasonable fits so the exact parameters determined are used primarily to illustrate that non-equilibrium processes are important for $\mathrm{U}(\mathrm{VI})$ transport in these sediments.

A retardation factor $(\mathrm{R})$ of 10.85 was obtained through the fitting of uranium profiles which resulted in $\mathrm{K}_{\mathrm{d}}$ values in the range of $1.90-2.03 \mathrm{~mL} / \mathrm{g}$ using equation (2) based on linear isotherm assumptions. The range of $\mathrm{K}_{\mathrm{d}}$ values obtained is similar to those previously determined for background sediments from Rifle area [up to $1.25 \mathrm{~mL} / \mathrm{g}$ ] (Hyun et al. 2009) and sediments from another former Uranium milling site in Colorado [ $3 \mathrm{~mL} / \mathrm{g}]$ (Davis et al. 2004); however, they are somewhat higher than the $\mathrm{K}_{\mathrm{d}}$ of $0.4 \mathrm{~mL} / \mathrm{g}$ determined from the present study's batch 
experiments. R values of 87 - 127 were obtained by fitting uranium profiles in Hanford column experiments (Qafoku et al. 2005).

\subsubsection{Sequential extractions}

Sequential extractions provided important information about the amounts and speciation of uranium in the sediments. Uptake amounts calculated for column A using the influent-effluent mass balance approach $(1.9 \pm 0.1 \mu \mathrm{g} / \mathrm{g})$ were very similar to those obtained through sequential extractions $(2.1 \pm 0.7 \mu \mathrm{g} / \mathrm{g})$. The uncertainty estimate on the amounts from the sequential extractions comes from four separate sources: the difference in sequential extractions of duplicate samples, the summation of uranium in each extraction step, the averaging of the uranium content from extractions performed on the inlet, middle, and outlet zones of the columns, and from the difference between the total extracted uranium from Column A (column with adsorbed uranium) and Column B (column with all uranium desorbed and only including the initial background uranium. The uptake amounts calculated for columns B and D using two different methods were within $30 \%$ of each other. Negligible amounts were extracted in the water soluble step. The dominant fractions of labile uranium were extracted in the step targeting ion exchangeable species and then in the weak acid extraction step (Figure 5a). Up to $1.5 \mu \mathrm{g} / \mathrm{g}$ of U was retrieved in the hot acid digestion step from the sediments both before and after loading of $\mathrm{U}$ in the columns. This amount of uranium is consistent with recalcitrant solid forms of uranium in the original Rifle sediments (Campbell et al. 2012) and was not included in the estimates of the amount of uranium taken up during the loading portion of the experiment. The amount of uranium in the background sediments shown in Figure 5 is for sediments that had undergone conditioning with SRGW that removed some labile U.

\subsection{Uranium release in the presence of phosphate}




\subsubsection{Aqueous phase analysis}

333 Uranium concentrations decreased faster for the phosphate-treated columns (Columns C and D)

334 than for the column (Column B) that was not treated with phosphate (Figure 6). Although this

335 observation might initially suggest that phosphate's presence resulted in faster uranium

336 desorption, the influent-effluent mass balance for the column indicated that more than $75 \%$ of

337 the adsorbed uranium $(1.51 \mu \mathrm{g} / \mathrm{g})$ was retained over $100 \mathrm{PV}$ of operation when phosphate was

338 present (Column D) in the influent (Table 3). The more rapid decrease to low concentrations

339 when phosphate was present was caused by enhanced retention of uranium by the sediments.

\section{$340 \quad 3.3 .2 \quad$ Sequential extractions}

341 Sequential extraction results confirmed the observations regarding phosphate's effect on uranium

342 retention. For sediments for which uranium was released after $132 \mathrm{PV}$ of uranium and

343 phosphate-free SRGW was flushed through the column (i.e. Column B, following the completion

344 of the release mode), almost no uranium was detectable in the first three extraction steps (Figure

345 5b). In contrast, when phosphate was added to the uranium-free influent during the release

346 mode, uranium retained was detectable and primarily in forms that could be mobilized by

347 ammonium acetate and acetic acid (Figure 5c). The extractions were carried out at $\mathrm{pH} 7$

348 (ammonium acetate) and pH 5 (acetic acid) and it is likely that not all adsorbed uranium was

349 desorbed or that not all precipitated uranium solids dissolved. Enhanced retention caused by

350 phosphate was probably due to adsorption or precipitation. Uniform distribution of uranium

351 along the length of the column suggests that adsorption was the dominant uranium uptake

352 mechanism. If uranium uptake had occurred through precipitation, then more uranium would

353 have been expected near the inlet where maximum supersaturation would have occurred as the

354 phosphate-containing influent first contacted the uranium-loaded sediments. 


\subsection{LIFS determination of likely U(VI) species present}

356 Fluorescence spectra of samples from Column A showed very little or no discernible

357 fluorescence spectral intensity (Figure 7). This behavior could be attributed to multiple reasons.

358 First, a weak broad spectral background could result from surface complexes (Wang et al. 2005).

359 Second, iron oxides in the sediments (Campbell et al. 2012, Komlos et al. 2008) could quench

360 fluorescence at room temperatures and result in poorly resolved spectra (Wang et al. 2011).

361 Finally, multiple quenching mechanisms are exhibited by the uranyl ion that could lead to

362 spectral broadening at room temperatures (Wang et al. 2005). However, analyzing the samples at

363 lower temperatures did not improve spectral intensities or resolution thereby suggesting that

364 fluorescence quenching was likely the result of the presence of surface complexes.

Fluorescence spectra for samples from Columns B and D had similar features (weak,

366 broad spectral background) to those for the samples from Column A. However, an additional

367 weak feature was observed for the sample obtained from the inlet end of column D, one of the

368 columns amended with phosphate (Figure 7). This additional feature does not match any of the

369 peaks observed for uranyl phosphate solids and thus suggests the presence of a different uranyl

370 species in addition to the surface complexes seen in samples from Column A. Addition of

371 phosphate might have resulted in formation of ternary uranyl phosphate complexes that led to

372 improved retention within the columns during the release phase or the precipitation of calcium-

373 phosphate solid onto which uranium was then bound. These results imply that uranium

374 immobilization occurred via adsorption. If the dominant mechanism had been precipitation, then

375 uranium distribution within the column should have been uneven or sediments should have had 376 distinct fluorescence spectral characteristics.

\section{4. Conclusions}


378 Aqueous phase and solid phase measurements demonstrate the enhanced retention of uranium 379 caused by phosphate addition to sediments. Sequential extractions revealed that uranium was 380 distributed uniformly within the columns. Higher retention in the presence of phosphate could be 381 due to enhanced adsorption of uranium through the formation of ternary surface complexes.

382 Batch sorption experiments confirmed that the $\mathrm{K}_{\mathrm{d}}$ for uranium adsorption increases by up to a 383 factor of 6 upon phosphate addition. Stopped flow events performed during the column 384 experiments confirmed that non-equilibrium processes were involved in controlling the U(VI) 385 transport during the adsorption and desorption modes. The non-equilibrium behavior is believed 386 to result from physical mass transfer processes and is attributed to intragrain diffusional mass 387 transfer limitations existing within local micro-environments.

A one-dimensional non-equilibrium CDE model was used to fit uranium and bromide 389 profiles and calculate the transport parameters. Fitting of the uranium and bromide profiles 390 yielded a retardation factor of 10.85 for uranium. Based on this retardation factor value, a 391 distribution coefficient $\left(\mathrm{K}_{\mathrm{d}}\right)$ was calculated that suggests that the Rifle sediments are relatively 392 weak adsorbents for uranium compared to those at other sites. At low carbonate concentrations 393 and at $\mathrm{pH}$ conditions ranging from slightly acidic to mildly alkaline, phosphate amendments may 394 be more effective for in situ uranium immobilization than that would be at the Rifle site.

The current study represents a scenario of phosphate addition to a site with most of the 396 uranium hosted within the sediments. The results from the examined scenario indicate that 397 uranium retention in the sediments can be achieved by phosphate addition. However, the extent 398 of this retention is relatively modest compared to the decreases in effluent uranium concentrations that can be achieved by sustained biological reduction (Sharp et al. 2011b) or that 400 could potentially be achieved at sites with more favorable conditions for U(VI) adsorption.. 


\section{Acknowledgements}

402 We are grateful to the McDonnell International Scholars Academy at Washington University for 403 providing the Ameren corporate fellowship for Vrajesh Mehta. This work was supported by the 404 U.S. Department of Energy (DOE) Subsurface Biogeochemical Research program (Award No. 405 DE-SC0006857). ICP-MS analysis was performed at the Nano Research Facility (NRF), a 406 member of the National Nanotechnology Infrastructure Network (NNIN), which was supported 407 by the National Science Foundation under Grant No. ECS-0335765. LIFS measurements were 408 performed at the Environmental Molecular Sciences Laboratory (EMSL), a national scientific 409 user facility sponsored by the DOE Office of Biological and Environmental Research and 410 located at the Pacific Northwest National Laboratory. PNNL is operated for DOE by Battelle 411 Memorial Institute under Contract \# DE-AC06-76RLO-1830. Sediments were kindly provided 412 by Ken Williams, Phil Long and the Rifle Integrated Field Research Challenge team. 
413

414

415

416

417

418

419

420

421

422

423

424

425

426

427

428

429

430

431

432

433

434

435

\section{References}

Ahmed, B., Cao, B., Mishra, B., Boyanov, M.I., Kemner, K.M., Fredrickson, J.K. and Beyenal, H. (2012) Immobilization of U(VI) from oxic groundwater by Hanford 300 Area sediments and effects of Columbia River water. Water Research 46(13), 3989-3998.

Arai, Y., Marcus, M.A., Tamura, N., Davis, J.A. and Zachara, J.M. (2007) Spectroscopic evidence for uranium bearing precipitates in vadose zone sediments at the hanford 300area site. Environmental Science and Technology 41(13), 4633-4639.

Arey, J.S., Seaman, J.C. and Bertsch, P.M. (1999) Immobilization of uranium in contaminated sediments by hydroxyapatite addition. Environmental Science and Technology 33(2), $337-342$.

Bargar, J.R., Reitmeyer, R. and Davis, J.A. (1999) Spectroscopic confirmation of uranium(VI)carbonato adsorption complexes on hematite. Environmental Science and Technology 33(14), 2481-2484.

Barnett, M.O., Jardine, P.M., Brooks, S.C. and Selim, H.M. (2000) Adsorption and transport of uranium(VI) in subsurface media. Soil Science Society of America Journal 64, 908-917.

Beazley, M.J., Martinez, R.J., Webb, S.M., Sobecky, P.A. and Taillefert, M. (2011) The effect of $\mathrm{pH}$ and natural microbial phosphatase activity on the speciation of uranium in subsurface soils. Geochimica Et Cosmochimica Acta 75(19), 5648-5663.

Bernhard, G., Geipel, G., Brendler, V. and Nitsche, H. (1998) Uranium speciation in waters of different uranium mining areas. Journal of Alloys and Compounds 271-273(0), 201-205.

Bernhard, G., Geipel, G., Reich, T., Brendler, V. and Amayri, S. (2001) Uranyl(VI) carbonate complex formation: Validation of the $\mathrm{Ca}_{2} \mathrm{UO}_{2}\left(\mathrm{CO}_{3}\right)_{3}$ (aq.) species. Radiochimica Acta 89(8/2001), 511-518. 
Bostick, B.C., Fendorf, S., Barnett, M.O., Jardine, P.M. and Brooks, S.C. (2002) Uranyl surface complexes formed on subsurface media from DOE facilities. Soil Science Society of America Journal 66(1), 99-108.

Brusseau, M.L., Hu, Q.H. and Srivastava, R. (1997) Using flow interruption to identify factors causing nonideal contaminant transport. Journal of Contaminant Hydrology 24(3-4), 205219.

Buck, E.C., Brown, N.R. and Dietz, N.L. (1996) Contaminant uranium phases and leaching at the Fernald site in Ohio. Environmental Science and Technology 30(1), 81-88.

Campbell, K.M., Veeramani, H., Urich, K.-U., Blue, L.Y., Giammar, D.E., Bernier-Latmani, R., Stubbs, J.E., Suvorova, E., Yabusaki, S., Lezama-Pacheco, J.S., Mehta, A., Long, P.E. and Bargar, J.R. (2011) Oxidative dissolution of biogenic uraninite in groundwater at Old Rifle, CO. Environmental Science and Technology 45(20), 8748-8754.

Campbell, K.M., Kukkadapu, R.K., Qafoku, N.P., Peacock, A.D., Lesher, E., Williams, K.H., Bargar, J.R., Wilkins, M.J., Figueroa, L., Ranville, J., Davis, J.A. and Long, P.E. (2012) Geochemical, mineralogical and microbiological characteristics of sediment from a naturally reduced zone in a uranium-contaminated aquifer. Applied Geochemistry 27(8), 1499-1511.

Catalano, J.G., McKinley, J.P., Zachara, J.M., Heald, S.M., Smith, S.C. and Brown, G.E. (2006) Changes in uranium speciation through a depth sequence of contaminated Hanford sediments. Environmental Science and Technology 40(8), 2517-2524.

Cheng, T., Barnett, M.O., Roden, E.E. and Zhuang, J.L. (2004) Effects of phosphate on uranium(VI) adsorption to goethite-coated sand. Environmental Science and Technology 38(22), 6059-6065. 
Crane, R.A., Dickinson, M., Popescu, I.C. and Scott, T.B. (2011) Magnetite and zero-valent iron nanoparticles for the remediation of uranium contaminated environmental water. Water Research 45(9), 2931-2942.

Davis, J.A., Meece, D.E., Kohler, M. and Curtis, G.P. (2004) Approaches to surface complexation modeling of uranium(VI) adsorption on aquifer sediments. Geochimica Et Cosmochimica Acta 68(18), 3621-3641.

DOE (1999) Final site observational work plan for the UMTRA project old rifle site GJO-99-88TAR. U.S Department of Energy, Grand Junction Office: Grand Junction, Colorado.

Dong, W., Tokunaga, T.K., Davis, J.A. and Wan, J. (2011) Uranium(VI) Adsorption and Surface Complexation Modeling onto Background Sediments from the F-Area Savannah River Site. Environmental Science and Technology 46(3), 1565-1571.

Dong, W.M. and Brooks, S.C. (2006) Determination of the formation constants of ternary complexes of uranyl and carbonate with alkaline earth metals $\left(\mathrm{Mg}^{2+}, \mathrm{Ca}^{2+}, \mathrm{Sr}^{2+}\right.$, and $\left.\mathrm{Ba}^{2+}\right)$ using anion exchange method. Environmental Science and Technology 40(15), 46894695.

Fang, Y., Yabusaki, S.B., Morrison, S.J., Amonette, J.P. and Long, P.E. (2009) Multicomponent reactive transport modeling of uranium bioremediation field experiments. Geochimica Et Cosmochimica Acta 73(20).

Fox, P.M., Davis, J.A., Hay, M.B., Conrad, M.E., Campbell, K.M., Williams, K.H. and Long, P.E. (2012) Rate-limited U(VI) desorption during a small-scale tracer test in a heterogeneous uranium-contaminated aquifer. Water Resources Research 48. 
Fuller, C.C., Bargar, J.R., Davis, J.A. and Piana, M.J. (2002) Mechanisms of uranium interactions with hydroxyapatite: Implications for groundwater remediation. Environmental Science and Technology 36(2), 158-165.

Giammar, D.E. and Hering, J.G. (2001) Time scales for sorption-desorption and surface precipitation of uranyl on goethite. Environmental Science and Technology 35(16), 33323337.

Greskowiak, J., Hay, M.B., Prommer, H., Liu, C., Post, V.E.A., Ma, R., Davis, J.A., Zheng, C. and Zachara, J.M. (2011) Simulating adsorption of U(VI) under transient groundwater flow and hydrochemistry: Physical versus chemical nonequilibrium model. Water Resources Research 47(8), W08501.

Hsi, C.K.D. and Langmuir, D. (1985) Adsorption of uranyl onto ferric oxyhydroxides Application of the surface complexation site-binding model. Geochimica Et Cosmochimica Acta 49(9), 1931-1941.

Hyun, S.P., Fox, P.M., Davis, J.A., Campbell, K.M., Hayes, K.F. and Long, P.E. (2009) Surface Complexation Modeling of U(VI) Adsorption by Aquifer Sediments from a Former Mill Tailings Site at Rifle, Colorado. Environmental Science and Technology 43(24).

Jensen, M.P., Nash, K.L., Morss, L.R., Appelman, E.H. and Schmidt, M.A. (1996) Humic and Fulvic Acids, pp. 272-285, American Chemical Society.

Jerden, J.L., Sinha, A.K. and Zelazny, L. (2003) Natural immobilization of uranium by phosphate mineralization in an oxidizing saprolite-soil profile: chemical weathering of the Coles Hill uranium deposit, Virginia. Chemical Geology 199(1-2), 129-157.

Jones, T.E., Wood, M.I., Corbin, R.A. and Simpson, B.C. (2001) Preliminary inventory estimates for single-shell tank leaks in B, BX, and BY Tank Farms. RPP-7389. 
Kohler, M., Curtis, G.P., Kent, D.B. and Davis, J.A. (1996) Experimental investigation and modeling of uranium(VI) transport under variable chemical conditions. Water Resources Research 32(12), 3539-3551.

Komlos, J., Peacock, A., Kukkadapu, R.K. and Jaffé, P.R. (2008) Long-term dynamics of uranium reduction/reoxidation under low sulfate conditions. Geochimica Et Cosmochimica Acta 72(15), 3603-3615.

Mehta, V.S., Maillot, F., Wang, Z., Catalano, J.G. and Giammar, D.E. (2014) Effect of cosolutes on the products and solubility of uranium(VI) precipitated with phosphate. Chemical Geology 364(0), 66-75.

Moon, H.S., McGuinness, L., Kukkadapu, R.K., Peacock, A.D., Komlos, J., Kerkhof, L.J., Long, P.E. and Jaffe, P.R. (2010) Microbial reduction of uranium under iron and sulfate reducing conditions: Effect of amended goethite on microbial community composition and dynamics. Water Research 44(14), 4015-4028.

Palmisano, A. and Hazen, T. (2003) Bioremediation of Metals and Radionuclides: What It Is and How It Works (2nd Edition). LBNL--42595-(2003); R\&D Project: 522201; TRN: US200405\%\%185 United States10.2172/820771R\&D Project: 522201; TRN: US200405\%\%185Tue Feb 05 04:53:47 EST 2008OSTI as DE00820771LBNLEnglish.

Parker, J.C. and Van Genuchten, M.T. (1984) Determining Transport Parameters from Laboratory and Field Tracer Experiments, Virginia Agricultural Experiment Station.

Payne, T.E., Davis, J.A. and Waite, T.D. (1996) Uranium adsorption on ferrihydrite - Effects of phosphate and humic acid. Radiochimica Acta 74, 239-243. 
Qafoku, N.P., Zachara, J.M., Liu, C.X., Gassman, P.L., Qafoku, O.S. and Smith, S.C. (2005) Kinetic desorption and sorption of $\mathrm{U}(\mathrm{VI})$ during reactive transport in a contaminated Hanford sediment. Environmental Science and Technology 39(9), 3157-3165.

Qafoku, N.P., Kukkadapu, R.K., McKinley, J.P., Arey, B.W., Kelly, S.D., Wang, C.M., Resch, C.T. and Long, P.E. (2009) Uranium in Framboidal Pyrite from a Naturally Bioreduced Alluvial Sediment. Environmental Science and Technology 43(22), 8528-8534.

Reardon, E.J. (1981) $\mathrm{K}_{\mathrm{d}}$ - Can they be used to describe reversible ion sorption reactions in contaminant migration? Ground Water 19(3), 279-286.

Sharp, J.O., Lezama-Pacheco, J.S., Schofield, E.J., Junier, P., Ulrich, K.-U., Chinni, S., Veeramani, H., Margot-Roquier, C., Webb, S.M., Tebo, B.M., Giammar, D.E., Bargar, J.R. and Bernier-Latmani, R. (2011a) Uranium speciation and stability after reductive immobilization in aquifer sediments. Geochimica Et Cosmochimica Acta 75(21), 64976510.

Sharp, J.O., Lezama-Pacheco, J.S., Schofield, E.J., Junier, P., Ulrich, K.U., Chinni, S., Veeramani, H., Margot-Roquier, C., Webb, S.M., Tebo, B.M., Giammar, D.E., Bargar, J.R. and Bernier-Latmani, R. (2011b) Uranium speciation and stability after reductive immobilization in aquifer sediments. Geochimica Et Cosmochimica Acta 75(21), 64976510.

Sherman, D.M., Peacock, C.L. and Hubbard, C.G. (2008) Surface complexation of U(VI) on goethite ( $\alpha-\mathrm{FeOOH})$. Geochimica Et Cosmochimica Acta 72(2), 298-310.

Singer, D.M., Zachara, J.M. and Brown, G.E. (2009) Uranium speciation as a function of depth in contaminated Hanford sediments - A micro-XRF, micro-XRD, and micro- and bulkXAFS study. Environmental Science and Technology 43(3), 630-636. 
547 548

549 550 551

Singh, A., Ulrich, K.U. and Giammar, D.E. (2010) Impact of phosphate on U(VI) immobilization in the presence of goethite. Geochimica Et Cosmochimica Acta 74(22), 6324-6343.

Singh, A., Catalano, J.G., Ulrich, K.U. and Giammar, D.E. (2012) Molecular-scale structure of uranium(VI) immobilized with goethite and phosphate. Environmental Science and Technology 46(12), 6594-6603.

Stewart, B.D., Mayes, M.A. and Fendorf, S. (2010) Impact of Uranyl-Calcium-Carbonato Complexes on Uranium(VI) Adsorption to Synthetic and Natural Sediments. Environmental Science and Technology 44(3), 928-934.

Tang, G., Mayes, M.A., Parker, J.C., Yin, X.L., Watson, D.B. and Jardine, P.M. (2009) Improving parameter estimation for column experiments by multi-model evaluation and comparison. Journal of Hydrology 376(3-4), 567-578.

Tessier, A., Campbell, P.G.C. and Bisson, M. (1979) Sequential extraction procedure for the speciation of particulate trace-metals. Analytical Chemistry 51(7), 844-851.

Toride, N., Leij, F.J. and van Genuchten, M.T. (1995) The CXTFIT Code for Estimating Transport Parameters from Laboratory or Field Tracer Experiments. Version 2.0.

Wang, Z.M., Zachara, J.M., Yantasee, W., Gassman, P.L., Liu, C.X. and Joly, A.G. (2004) Cryogenic laser induced fluorescence characterization of U(VI) in hanford vadose zone pore waters. Environmental Science and Technology 38(21), 5591-5597.

Wang, Z.M., Zachara, J.M., Gassman, P.L., Liu, C.X., Qafoku, O., Yantasee, W. and Catalano, J.G. (2005) Fluorescence spectroscopy of U(VI)-silicates and U(VI)-contaminated Hanford sediment. Geochimica Et Cosmochimica Acta 69(6), 1391-1403.

Wang, Z.M., Zachara, J.M., Boily, J.F., Xia, Y.X., Resch, T.C., Moore, D.A. and Liu, C. (2011) Determining individual mineral contributions to U(VI) adsorption in a contaminated 
aquifer sediment: A fluorescence spectroscopy study. Geochimica Et Cosmochimica Acta

571 75(10), 2965-2979.

572 Wellman, D.M., Glovack, J.N., Parker, K., Richards, E.L. and Pierce, E.M. (2008) Sequestration

573 and retention of uranium(VI) in the presence of hydroxylapatite under dynamic

574 geochemical conditions. Environmental Chemistry 5(1), 40-50.

575 Yabusaki, S.B., Fang, Y., Long, P.E., Resch, C.T., Peacock, A.D., Komlos, J., Jaffe, P.R., 576 Morrison, S.J., Dayvault, R.D., White, D.C. and Anderson, R.T. (2007) Uranium removal from groundwater via in situ biostimulation: Field-scale modeling of transport and

578 biological processes. Journal of Contaminant Hydrology 93(1-4).

579 


\section{$581 \quad$ Figure Captions}

582 Figure 1. Experimental modes of operation to study the transport of U(VI) through sediments 583 amended with phosphate to induce in situ uranium immobilization.

584 Figure 2. Equilibrium uranium sorption on Rifle sediments (250 g/L) after 2 days of reaction 585 with SRGW for three phosphate concentrations. Trendline(s) included for different starting 586 phosphate concentrations were used to determine $\mathrm{K}_{\mathrm{d}}$ values of $0.4,0.6$ and $2.2 \mathrm{~mL} / \mathrm{g}$ for 0,100 , 587 and $1000 \mu \mathrm{M}$ P respectively. Only data points for which uranium uptake can be unambiguously 588 assigned to adsorption have been included.

589 Figure 3. Uranium and bromide breakthrough profiles (uptake phase) for Columns A-D

590 following the conditioning phase of the experiments. Two 12-hour stopped flow events (SFE) are 591 also included. Representative bromide data for Column A are shown with open cross symbols, 592 and closed symbols represent uranium data for columns A-D (1 pore volume $(\mathrm{PV})=3.50 \pm 0.25$ 593 h). The inset provides a closer view of a stopped flow event for Column D.

594 Figure 4. Uranium and bromide profiles during both uptake and release phase (observed and 595 fitted using non-equilibrium CDE) for Column B (a) and Column D (b). The release phase of 596 Column D (with phosphate) was not included for uranium fitting because reactions other than 597 adsorption-desorption were likely occurring. Symbols represent the normalized concentrations 598 for bromide and uranium as a function of flow in pore volumes. Dashed and solid lines represent 599 fitted profiles for uranium and bromide respectively.

600 Figure 5. Sequential extraction results for uranium extracted from three depth increments of 601 Column A, B and D. Results of Background sediments are shown for reference. Error bars 602 represent standard error for the data obtained through duplicate samples. 
603 Figure 6. Uranium release profiles from Columns B-D following the end of the uptake mode.

604 SRGW with (Columns C-D) or without (Column B) phosphate was started at $~ 353$ hours

605 (vertical black dashed line). Stopped flow events (SFE) of 12 hours are also shown. Column C

606 was stopped and sampled after 2 PVs of phosphate-treatment $(7.5 \mathrm{~h})$. Closed symbols represent

607 uranium data from different columns ( $1 \mathrm{PV}=3.5 \pm 0.25 \mathrm{~h})$. The inset shows the stopped flow

608 events for Column B.

609 Figure 7. Fluorescence spectra of samples obtained from different depths within the columns.

610 Inlet, midsection, and outlet represent samples obtained from different portions of the columns.

611 Spectra of metaschoepite, chernikovite and sodium autunite reference materials are included for 612 comparison. 
Table 1. Composition of the Synthetic Rifle Ground Water

\begin{tabular}{ll}
\hline Analyte & Concentration (mM) \\
\hline $\mathrm{Na}$ & 11.00 \\
$\mathrm{Ca}$ & 5.00 \\
$\mathrm{Mg}$ & 4.94 \\
$\mathrm{~K}$ & 0.33 \\
$\mathrm{U}(\mathrm{VI})^{\mathrm{a}}$ & $0 / 4 \times 10^{-3}$ \\
$\mathrm{Li}^{\mathrm{b}}$ & 0.13 \\
$\mathrm{DIC}^{\mathrm{c}}$ & 7.44 \\
$\mathrm{SO}_{4}$ & 10.78 \\
$\mathrm{Cl}$ & 3.00 \\
$\mathrm{NO}_{3}$ & 0.53 \\
$\left.\mathrm{Si}^{(\mathrm{OH}}\right)_{4}$ & 0.28 \\
$\mathrm{PO}_{4}{ }^{\mathrm{a}}$ & $0 / 1.00$ \\
$\mathrm{Br}^{\mathrm{b}}$ & 0.13 \\
$\mathrm{pH}^{\mathrm{m}}$ & 7.10 \\
\hline
\end{tabular}

${ }^{a}$ Concentration of 0 corresponds to experimental conditions without any addition of U(VI) or $\mathrm{PO}_{4}{ }^{3-}$ in the influent feed

${ }^{\mathrm{b}}$ Lithium (Li) and bromide (Br) were added as conservative tracers with the influent to aid in the calculation of transport parameters.

${ }^{c}$ DIC stands for dissolved inorganic carbon 
Table 2. Steps in the sequential extraction method

\begin{tabular}{lllll}
\hline Step & Target phase & Extractant composition & pH & Procedure \\
\hline 1 & Water soluble & Ultrapure water & 5.5 & $\begin{array}{l}\text { Shake suspension } 16 \mathrm{~h} . \\
\text { Shake suspension } 16 \mathrm{~h} .\end{array}$ \\
2 & Ion exchangeable & $1 \mathrm{M}$ ammonium acetate & 7.0 & $\begin{array}{l}\text { Rinse with ultrapure water. } \\
\text { Ring }\end{array}$ \\
3 & $\begin{array}{l}\text { Acid } \\
\text { soluble/Carbonate }\end{array}$ & $1 \mathrm{M}$ acetic acid & $5.0^{\mathrm{a}}$ & $\begin{array}{l}\text { Shake suspension } 16 \mathrm{~h} . \\
\text { Rinse with ultrapure water. }\end{array}$ \\
4 & Residual solids & $\begin{array}{l}8 \mathrm{~mL} \mathrm{HNO} \text { acid }+2 \mathrm{~mL} \mathrm{HCl} \\
\text { acid }+40 \mathrm{~mL} \mathrm{DI} \mathrm{water}\end{array}$ & -- & $\begin{array}{l}\text { Digest in heated block held } \\
\text { at } 100^{\circ} \mathrm{C} \text { for } 4 \mathrm{~h} .\end{array}$ \\
\hline
\end{tabular}

${ }^{\mathrm{a}}$ Sodium hydroxide was added to acetic acid solution to raise the $\mathrm{pH}$ levels to 5.0. 
Table 3. Uranium concentrations in the sediments calculated using mass balance approach

\begin{tabular}{lcccc}
\hline Mass of U $(\boldsymbol{\mu g} / \mathbf{g})^{\mathbf{1}}$ & Col. A & Col. B & Col. C & Col. D \\
\hline $\begin{array}{l}\text { Released during } \\
\text { conditioning phase }\end{array}$ & $0.21 \pm 0.02$ & $0.20 \pm 0.01$ & $0.21 \pm 0.01$ & $0.18 \pm 0.01$ \\
$\begin{array}{l}\text { Adsorbed during uptake } \\
\text { phase }\end{array}$ & $1.90 \pm 0.13$ & $1.68 \pm 0.12$ & $1.69 \pm 0.12$ & $1.98 \pm 0.14$ \\
$\begin{array}{l}\text { Desorbed during release } \\
\text { phase }\end{array}$ & -- & $1.95 \pm 0.14$ & -- & $0.47 \pm 0.03$ \\
Retained or Accumulated & -- & $-0.27 \pm 0.18^{2}$ & -- & $1.51 \pm 0.14$ \\
\hline
\end{tabular}

\footnotetext{
${ }^{1}$ Uncertainty estimates come from the propagation of uncertainty in the summation of multiple influent and effluent samples (equation 8) used to estimate the total $U$ amounts taken up or released.

${ }^{2}$ The number (negative concentration) is statistically not significantly different from zero.
} 


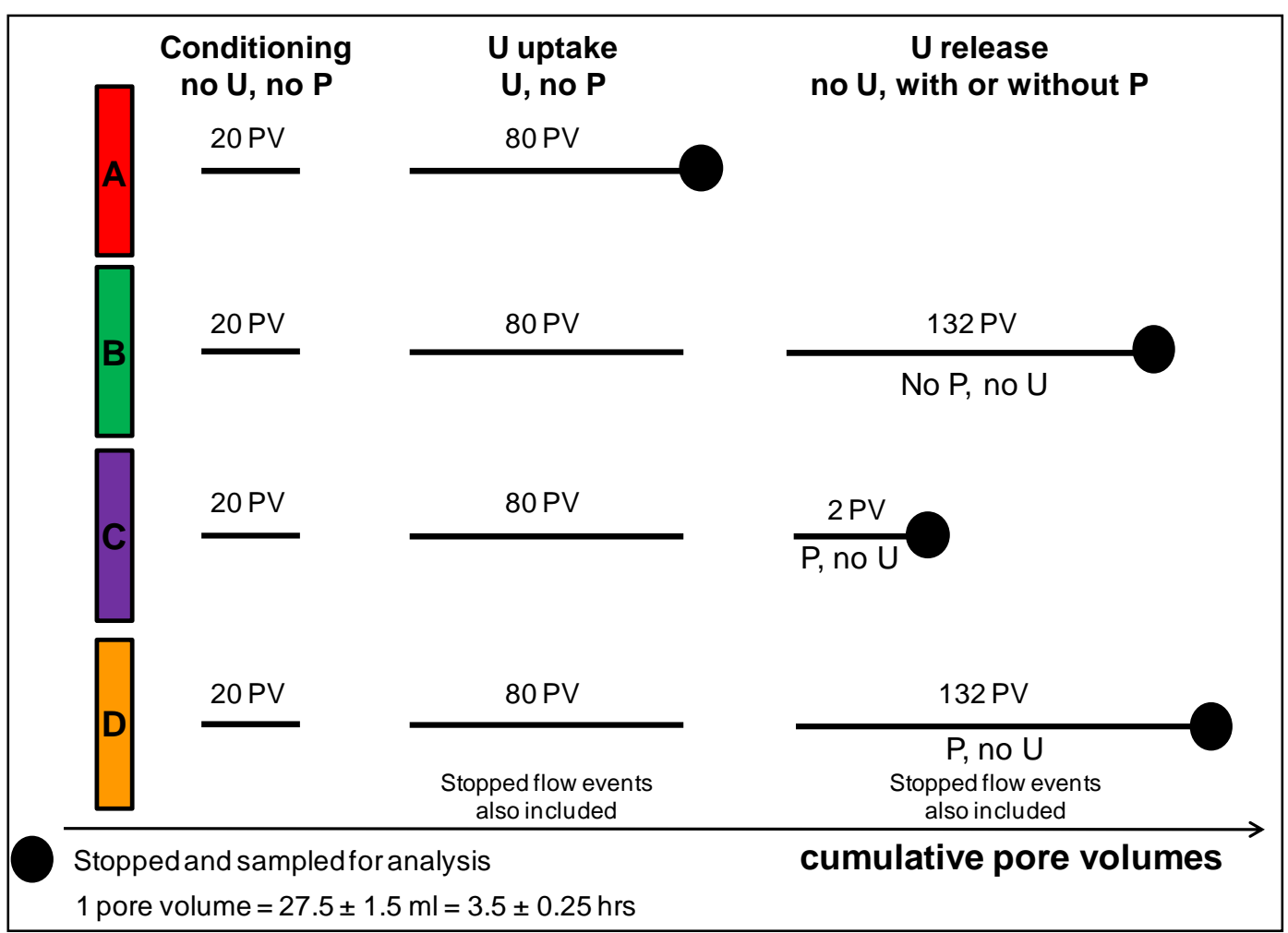

Figure 1. Experimental modes of operation to study the transport of U(VI) through sediments amended with phosphate to induce in situ uranium immobilization. 


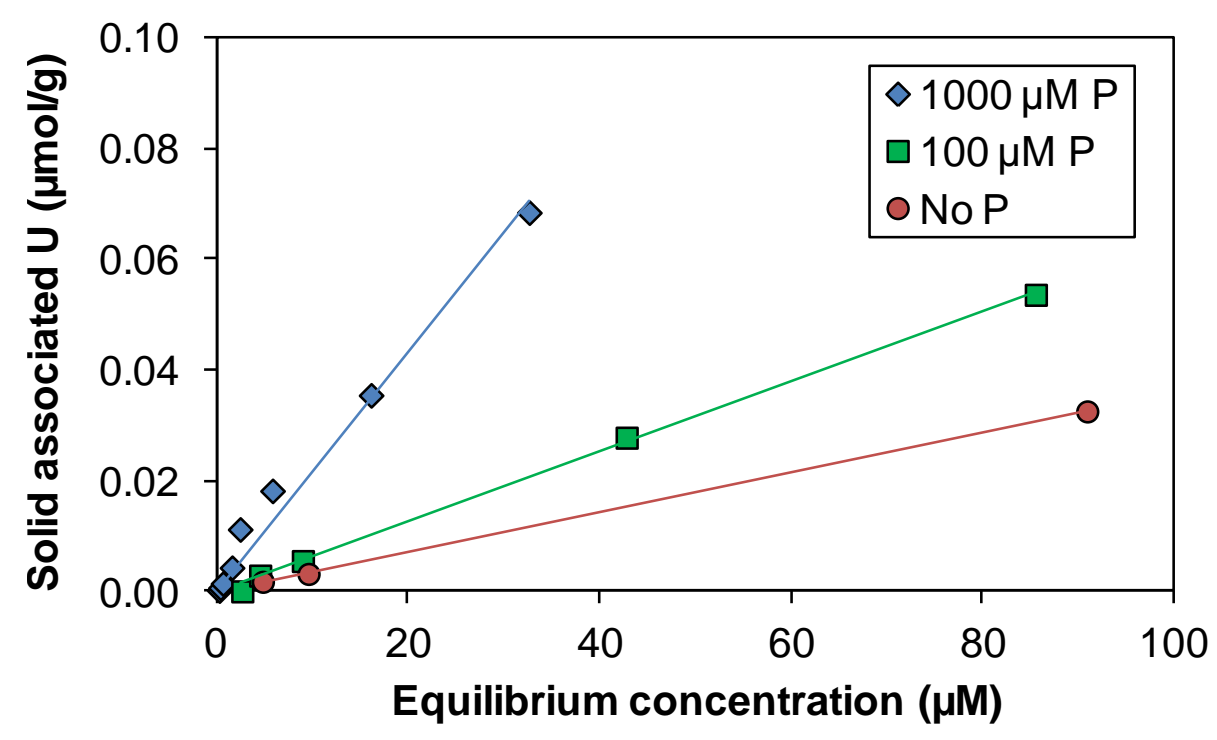

Figure 2. Equilibrium uranium sorption on Rifle sediments ( $250 \mathrm{~g} / \mathrm{L})$ after 2 days of reaction with SRGW for three phosphate concentrations. Trendline(s) included for different starting phosphate concentrations were used to determine $\mathrm{K}_{\mathrm{d}}$ values of $0.4,0.6$ and $2.2 \mathrm{~mL} / \mathrm{g}$ for 0,100 , and $1000 \mu \mathrm{M}$ P respectively. Only data points for which uranium uptake can be unambiguously assigned to adsorption have been included. 


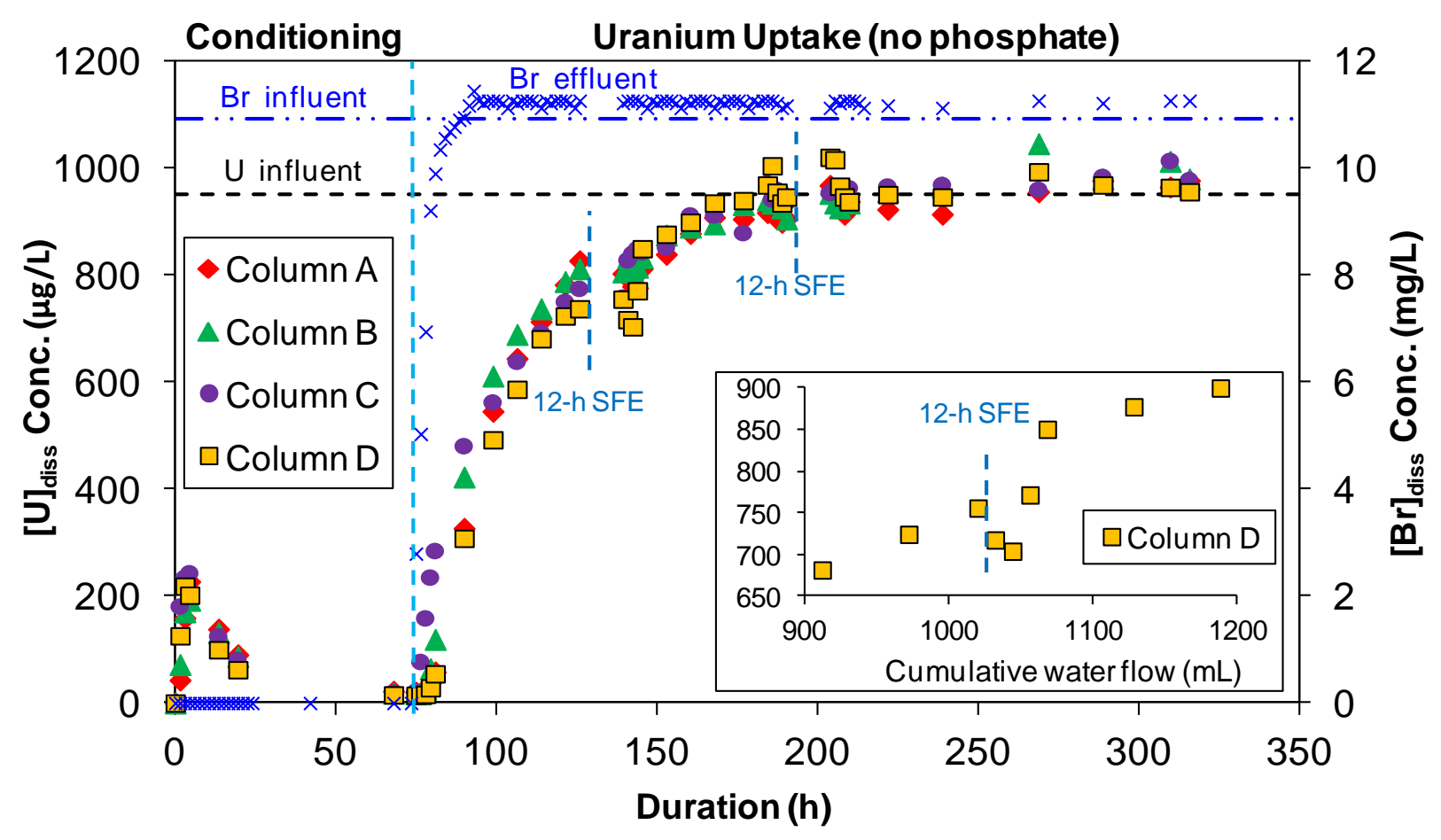

Figure 3. Uranium and bromide breakthrough profiles (uptake phase) for Columns A-D following the conditioning phase of the experiments. Two 12-hour stopped flow events (SFE) are also included. Representative bromide data for Column A are shown with open cross symbols, and closed symbols represent uranium data for columns A-D ( 1 pore volume $(\mathrm{PV})=3.50 \pm 0.25$ h). The inset provides a closer view of a stopped flow event for Column D. 

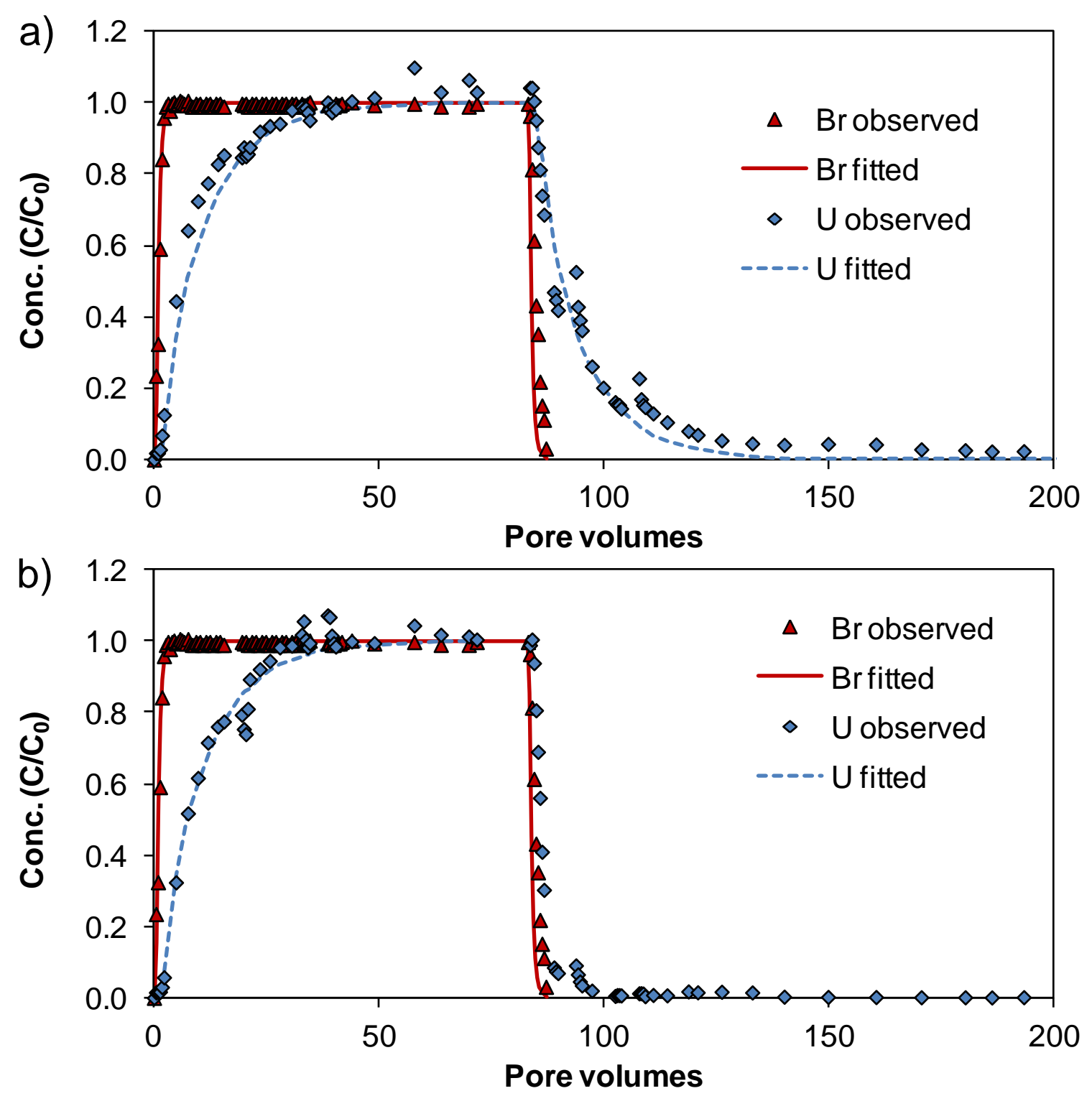

Figure 4. Uranium and bromide profiles during both uptake and release phase (observed and fitted using non-equilibrium CDE) for Column B (a) and Column D (b). The release phase of Column D (with phosphate) was not included for uranium fitting because reactions other than adsorption-desorption were likely occurring. Symbols represent the normalized concentrations for bromide and uranium as a function of flow in pore volumes. Dashed and solid lines represent fitted profiles for uranium and bromide respectively. 

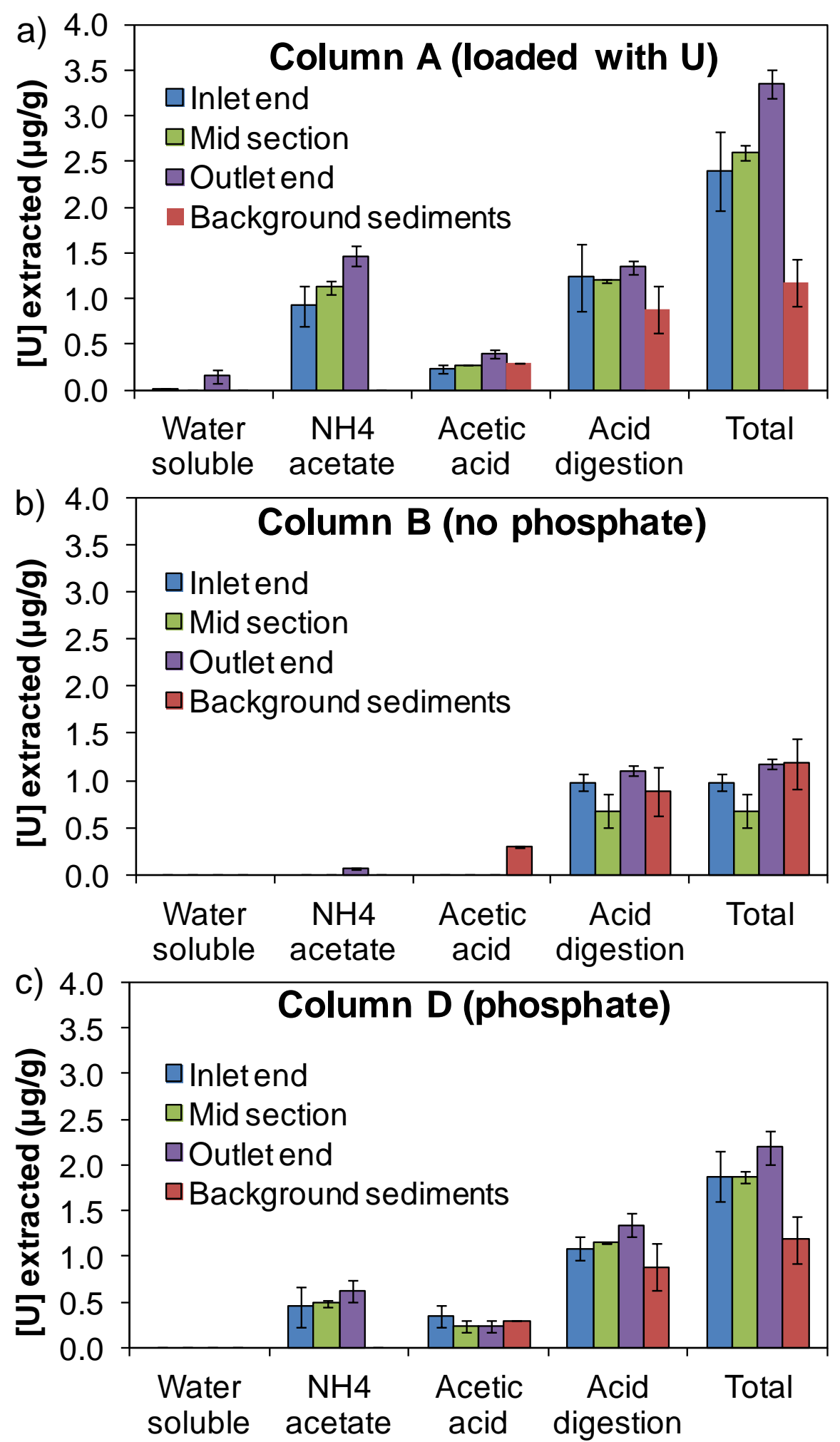

Figure 5. Sequential extraction results for uranium extracted from three depth increments of Columns A, B and D. Results of background sediments are shown for reference. Error bars represent standard error for the data obtained from duplicate samples. 


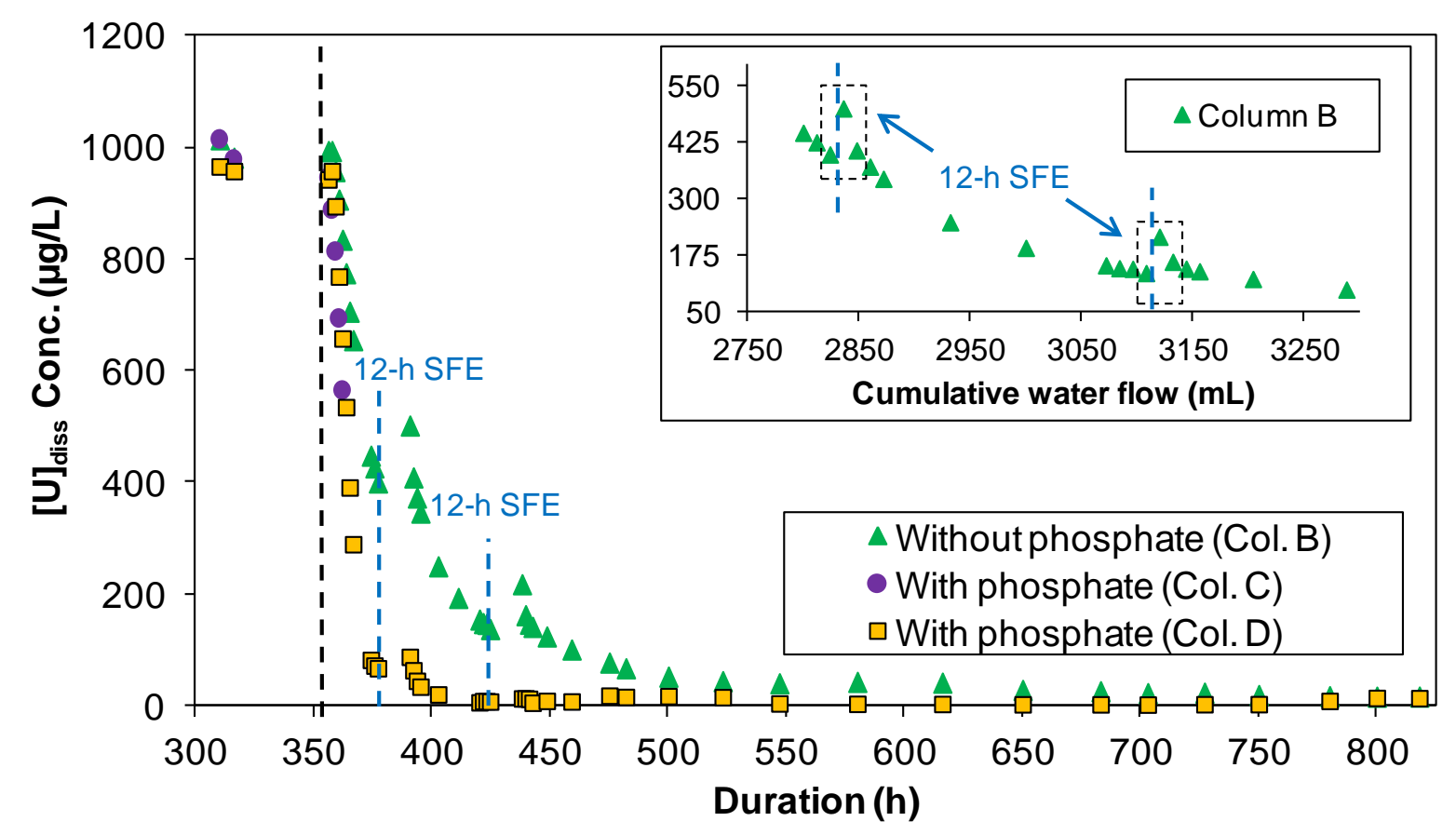

Figure 6. Uranium release profiles from Columns B-D following the end of the uptake mode. SRGW with (Columns C-D) or without (Column B) phosphate was started at 353 hours (vertical black dashed line). Stopped flow events (SFE) of 12 hours are also shown. Column C was stopped and sampled after $2 \mathrm{PV}$ s of phosphate-treatment $(7.5 \mathrm{~h})$. Closed symbols represent uranium data from different columns $(1 \mathrm{PV}=3.5 \pm 0.25 \mathrm{~h})$. The inset shows the stopped flow events for Column B. 


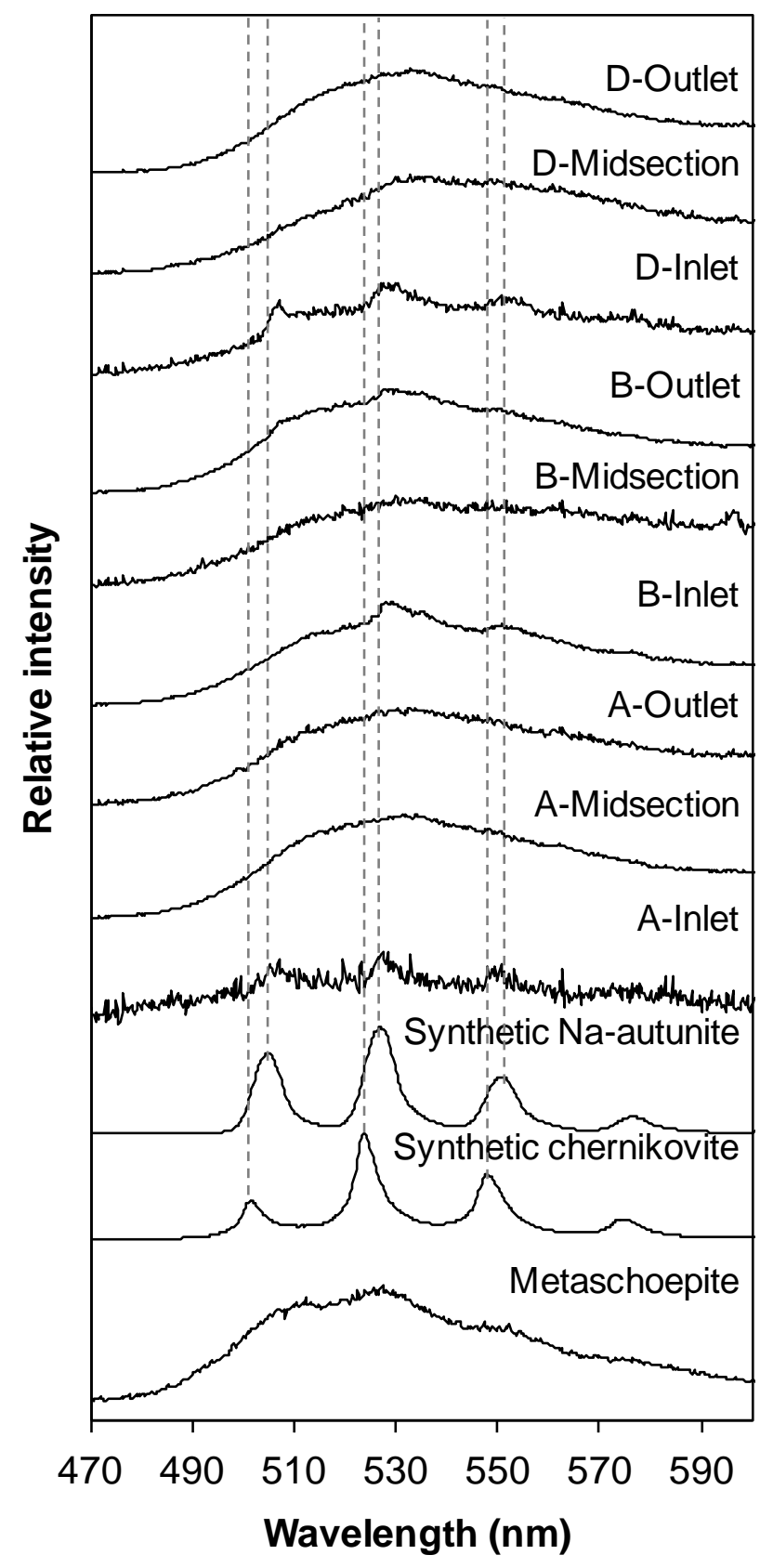

Figure 7. Fluorescence spectra of samples obtained from different depths within the columns. Inlet, midsection, and outlet represent samples obtained from different portions of the columns. Spectra of metaschoepite, chernikovite and sodium autunite reference materials are included for comparison. 